\title{
Medical students protest steadily rising tuition
} fees

\author{
— Cite as: CMAJ 2018 October 1;190:E1177-8. doi: 10.1503/cmaj.109-5654
}

Posted on cmajnews.com on Sept. 12, 2018.

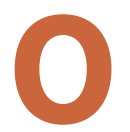
ntario medical tuition rates have increased by about $5 \%$ every year since 2000, according to an analysis by the Ontario Medical Students Association (OMSA). This steady rise follows a $116 \%$ leap over three years that started in 1997 when tuition increases were deregulated by the provincial government. According to Statistics Canada, the average cost of medical school tuition in Ontario is \$25541 per year, almost twice as high as the Canadian average of $\$ 14444$.

Nawid Sayed, coauthor of the analysis and policy lead on OMSA's education committee, fears that the rising cost of medical education may be warping the demographics of the profession. He cites a study showing that Ontario medical students came from increasingly affluent backgrounds in the years after fee deregulation. Growing social distance may put poorer patients at a disadvantage, Sayed says. He worries that physicians will be less able to sympathize or connect with patients because they come from such different backgrounds.

The OMSA analysis offers three approaches to make medical education more financially accessible. One option is for students to fund their medical education entirely through Ontario Student Assistance Program loans, rather than by taking on expensive lines of credit. This proposal, which Sayed describes as the "strongest and most unique argument," would save students about $\$ 10000$ in credit interest payments over a four-year medical degree.

A second proposal suggests freezing tuition rates to counter recent hikes. This option, which Sayed says is "probably the most easily acceptable," would save students about $\$ 8000$.
Banks and the provincial government could also allow medical students to delay loan repayment until after residency.

According to Stephanie Smith, president-elect of the Canadian Federation of Medical Students (CFMS), changes in medical education may be contributing to rising tuition rates across Canada. Sometimes the very things that make a school appealing, such as advanced simulation labs or smaller class sizes, also drive up costs, she explains.

Medical schools might be able to cut these costs by creating collaborative curriculums, a possibility the CFMS has been discussing for years, says Smith. For example, a university with special expertise could produce a podcast or video to share with other schools across the country.

Grants and financial awards can also help. The CFMS offers leadership awards to students and is working on creating new awards. Recognizing students who work in rural and low-income areas is a priority, Smith says.

Like Sayed, Smith is concerned that rising tuition rates could prevent people from low-income families from pursuing medicine. She also worries that medical

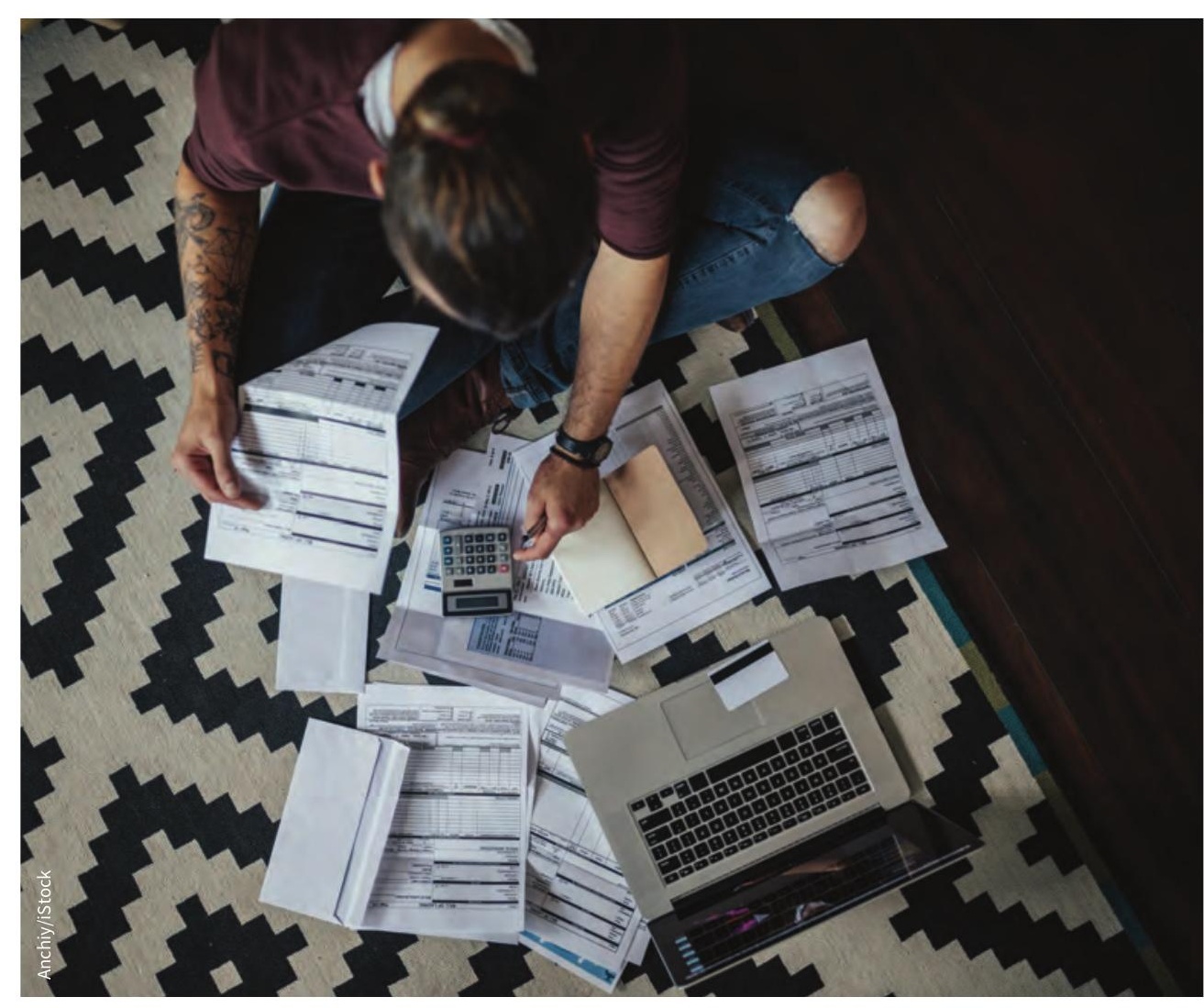

Rising cost of medical tuition may shut out students from less affluent backgrounds, trainees warn. 
students may also gravitate toward higherpaying specialties after graduation because of debt. And financial pressure may make physicians "more likely to see patients much quicker," in order to bill for a higher volume of patients, she says.

These concerns preoccupy medical educators, too, according to Dr. Richard
Reznick, dean of Queen's University's Faculty of Health Sciences. In a letter responding to concerns from the university's medical student association, Reznick explained that "the real cost of medical education far outweighs what the university receives as revenue." And many factors outside a university's control, includ- ing rising costs of living, may contribute to student debt. According to the letter, Reznick and the medical school leadership team have lobbied the budget office for the last five years to keep tuition increases to a minimum.

Caroline Mercer, Toronto, Ont. 